\title{
Inhibitory effect of $17 \beta$-estradiol on triglyceride synthesis in skeletal muscle cells is dependent on ESR1 and not ESR2
}

\author{
QUAN LIU ${ }^{1 *}$, RUI LI $^{1 *}$, GUANJUN CHEN $^{2}$, JIANMING WANG $^{3}$, BINGFENG HU $^{1}$, \\ CHAOFEI LI ${ }^{4}$, XIAOHUAN ZHU ${ }^{5}$ and YUNXIA LU ${ }^{4,6}$ \\ ${ }^{1}$ Department of Clinical Pharmacy, Class 2014, School of Pharmacy; ${ }^{2}$ Center of Scientific Research, Anhui Medical University, \\ Hefei, Anhui 230032; ${ }^{3}$ Dalian Maple International School, Dalian, Liaoning $116100 ;{ }^{4}$ The Comprehensive Laboratory, \\ Anhui Medical University; ${ }^{5}$ Department of Endocrinology, The First Affiliated Hospital of Anhui Medical University; \\ ${ }^{6}$ Department of Biochemistry and Molecular Biology, Anhui Medical University, Hefei, Anhui 230032, P.R. China
}

Received July 13, 2018; Accepted March 13, 2019

DOI: $10.3892 / \mathrm{mmr} .2019 .10189$

\begin{abstract}
The present study aimed to investigate the inhibitory effects and the mechanisms underlying $17 \beta$-estradiol $\left(\mathrm{E}_{2}\right)$ effects on triglyceride synthesis and insulin resistance in skeletal muscle tissues and cells. Ovariectomy (OVX) was performed on 6-month-old female rats treated with or without $\mathrm{E}_{2}$. Subsequently, various serum biochemical markers were measured. Additionally, pathological alterations of the uterus, liver and skeletal muscle were analyzed, and the content of triglycerides (TG) in muscle was detected. Differentiated myotubes formed by $\mathrm{C} 2 \mathrm{C} 12$ cells were treated with palmitic acid (PA) or pretreated with $\mathrm{E}_{2}$, estrogen receptor (ESR) 1 agonist propylpyrazoletriol (PPT) and ESR2 agonist diarylpropionitrile (DPN). Subsequently, the mRNA or protein expression levels of ESR $1 / 2$, peroxisome proliferator activated receptor $\alpha(\mathrm{PPAR} \alpha), \mathrm{CD} 36$ molecule (CD36), fatty acid synthase (FASN), perilipin 2 (PLIN2), phosphorylated acetyl-CoA carboxylase $\alpha$ (p-ACACA), p-AKT serine/threonine kinase (p-AKT) and p-mitogen-activated protein kinase 8 (p-MAPK8) were analyzed in skeletal muscle or in $\mathrm{C} 2 \mathrm{C} 12$ cells by reverse transcription-semi-quantitative polymerase chain reaction and western blotting. The present results suggested that treatment with $\mathrm{E}_{2}$ inhibited OVX-induced body weight gain, TG accumulation and insulin resistance. The protein or mRNA expression levels of ESR1, CD36, PPAR $\alpha, p-A C A C A$ and $\mathrm{p}$-AKT were decreased, whereas the protein or mRNA expression levels of ESR2, PLIN2, FASN and p-MAPK8 were increased in the OVX group. Of
\end{abstract}

Correspondence to: Dr Yunxia Lu, Department of Biochemistry and Molecular Biology, Anhui Medical University, 81 Meishan Road, Hefei, Anhui 230032, P.R. China

E-mail:wwwdluyx@sina.com

${ }^{*}$ Contributed equally

Key words: estrogen, fatty acid metabolism, ovariectomy, skeletal muscle, estrogen receptor note, treatment with $\mathrm{E}_{2}$ restored the expression levels of the aforementioned factors. In $\mathrm{C} 2 \mathrm{C} 12$ cells, treatment with $\mathrm{E}_{2}$ or PPT reversed the alterations induced by treatment with PA. In contrast, pretreatment with DPN did not influence the effect of PA. Collectively, $\mathrm{E}_{2}$ was able to interact with ESR1, thus activating the CD36-PPAR $\alpha$ pathway, decreasing the level of TG in the muscles and improving insulin resistance in skeletal muscles and $\mathrm{C} 2 \mathrm{C} 12$ cells.

\section{Introduction}

The three principal muscle types in mammals are cardiac, smooth and skeletal muscles, with skeletal muscle being the most abundant tissues in the human body (1). Although previous studies identified sex-specific differences in the physiopathological characteristics of the cardiovascular system (2), the sex-specific physiopathological properties of skeletal muscles remain unclear. A previous study demonstrated that $>3,000$ genes were differentially expressed between male and female skeletal muscle (3).

In mammals, there are three principal types of estrogens: Estrone, 17 $\beta$-estradiol $\left(\mathrm{E}_{2}\right)$ and estriol. $\mathrm{E}_{2}$, which exhibits increased biological activity compared with other estrogens, is secreted primarily by the growing follicles in the ovaries during the ovarian cycle (4). Notably, skeletal muscles are targeted by $\mathrm{E}_{2}(5)$. During perimenopausal and postmenopausal periods, there is a significant decrease in muscle strength that may be increased by hormonal replacement therapy (HRT), suggesting that estrogens are important modulators of muscle physiology and are able to affect gene expression and mitochondrial function, thus maintaining the bioenergetic status of muscle cells (6).

In addition to the regulation of reproductive functions, estrogens may affect various physiological functions, including cellular metabolism $(7,8)$. Decreased levels of $E_{2}$ following menopause or ovariectomy (OVX) are associated with hyperphagia, obesity, hepatic steatosis and triglycerides (TG) accumulation in skeletal muscle cells (9-11); however the molecular mechanisms underlying $\mathrm{E}_{2}$ function remain unclear. Due to their lipophilic properties, estrogens are able to diffuse through the cellular membranes, interacting with intracellular 
receptors (12). In total, there are two types of estrogen receptors (ESR): ESR1 and ESR2.

Previous studies demonstrated that the effects of $E_{2}$ on energy homeostasis are primarily mediated by $\operatorname{ESR} 1(10,13)$. Activating ESR1 using propylpyrazoletriol (PPT) may affect metabolism, insulin resistance and mitochondrial function in OVX mice with metabolic syndrome (14); however, the molecular mechanism underlying ESR1 function remains unclear.

Skeletal muscles are able to oxidize non-esterified fatty acids, or to store fatty acids (FAs) as TG, accumulating intramuscular triacylglycerol (IMTAG) (15). Although physiological levels of IMTAG do not impair the metabolic functions of skeletal muscles, the accumulation of IMTAG may be associated with promoted insulin resistance, due to increased levels of lipid intermediates and the subsequent activation of inflammatory or stress-associated pathway (16). Estrogen increases the levels of the FA transporter CD36 molecule (CD36) in the plasma membrane of cardiomyocytes, thus serving cardioprotective roles (17). Therefore, in the present study, it was hypothesized that $\mathrm{E}_{2}$ may increase CD36-mediated FA uptake, inhibiting the synthesis of FA and TG in skeletal muscle.

The transcription factor peroxisome proliferator activated receptor $\alpha(\operatorname{PPAR} \alpha)$ is expressed primarily in tissues exhibiting high rates of FA oxidation, including cardiac and skeletal muscles (18). PPAR $\alpha$ may regulate the protein expression levels of factors involved in FA catabolism. PPAR $\alpha$ activation was identified to improve the musculoskeletal effects of exercise during estrogen deficiency (19); however, its roles in CD36-mediated FA uptake and the synthesis of acetyl-CoA carboxylase $\alpha$ (ACACA), fatty acid synthetase (FASN) and perilipin 2 (PLIN2) remain unclear.

Although the potential health risks and benefits of long-term HRT remain unclear, future studies using short-term HRT or specific ER agonists including PPT and diarylpropionitrile (DPN), may provide novel insights into the effects of $E_{2}$ on skeletal muscles, thus benefiting postmenopausal patients (20). Therefore, it was hypothesized that short-term HRT may inhibit TG synthesis in the skeletal muscles of female rats following OVX, and this effect may be associated with the role of FA in promoting the activity of PPAR $\alpha$ following the interaction between $E_{2}$, and ESR1 or 2. To investigate this hypothesis, in vivo experiments were performed to examine the effects of $\mathrm{E}_{2}$ on weight loss and TG synthesis inhibition in female rats following OVX. Additionally, in vitro experiments were performed using ER agonists, including PPT and DPN, to activate ESR1 or ESR2, thus promoting FA transport, inhibiting TG synthesis and improving insulin resistance. Palmitic acid (PA) is the principal saturated FA in the blood, and was selected to treat myotubes formed by differentiated $\mathrm{C} 2 \mathrm{C} 12$ cells in order to investigate the mechanisms underlying $\mathrm{E}_{2}$-mediated TG synthesis and insulin resistance.

\section{Materials and methods}

Animals. A total of 30 female Sprague-Dawley rats (age, 6 months; weight, 300-350 g) were purchased from The Experimental Animal Center at Anhui Medical University (Hefei, China). All rats had free access to food and water and were maintained in standard conditions of controlled temperature and humidity $\left(22 \pm 1^{\circ} \mathrm{C}, 60-70 \%\right)$ under a 12 -h light/dark cycle for one week. All animal experiments were reviewed and approved by The Ethics Committee of Anhui Medical University.

Experimental protocol. Rats were randomly divided into three groups: i) Sham surgery (SHAM; $n=10)$; ii) rats that underwent ovariectomy without treatment $(\mathrm{OVX} ; \mathrm{n}=10)$; and iii) rats that underwent ovariectomy and treated with $\mathrm{E}_{2}\left(\mathrm{OVX}+\mathrm{E}_{2}\right.$; $\mathrm{n}=10$ ). All groups underwent laparotomy; however, the OVX and $\mathrm{OVX}+\mathrm{E}_{2}$ groups underwent bilateral ovariectomy. The OVX $+\mathrm{E}_{2}$ rats were injected with $\mathrm{E}_{2}$ (Sigma-Aldrich; Merck KGaA, Darmstadt, Germany) at a concentration of $0.06 \mathrm{mg} / \mathrm{kg} /$ day for 3 months following surgery. Body weight and food intake were measured every week.

Glucose tolerance test (GTT) and insulin tolerance test (ITT). Insulin sensitivity was assessed using GTT and ITT as previously described (21). Briefly, for the GTT assay, all rats were fasted overnight and administered glucose $(2 \mathrm{~g} / \mathrm{kg})$ by intraperitoneal injection. Blood samples were obtained from the tail veins at $0,30,60,90$ and 120 min following injection. The blood glucose was measured with a glucometer (OneTouch Ultra; Johnson \& Johnson, New Brunswick, NJ, USA). ITT assays were performed by the intraperitoneal injection of neutral insulin $(1 \mathrm{U} / \mathrm{kg}$ ) following fasting for 4-6 h. The blood glucose was measured at 0, 30, 45, 60, 90 and $120 \mathrm{~min}$. All data were plotted as blood glucose concentration over time. Subsequently, the area under curve (AUC) was calculated.

Serum lipid levels and $E_{2}$ assays. After 6 months, rats were fasted for $12 \mathrm{~h}$ and anesthetized by intraperitoneal injection of sodium pentobarbital $(60 \mathrm{mg} / \mathrm{kg})$. Blood $(\sim 10 \mathrm{ml})$ was collected in tubes and serum was separated by centrifuging the samples at $1,000 \mathrm{x}$ for $10 \mathrm{~min}$ at room temperature and stored at $-80^{\circ} \mathrm{C}$ prior to biochemical analysis. Fasting $\mathrm{TG}$, total cholesterol (TC), low-density lipoprotein cholesterol (LDL-C) and high-density lipoprotein cholesterol (HDL-C) levels were measured using an automatic biochemical analyzer (AU640; Olympus Corporation, Tokyo, Japan). The serum levels of $\mathrm{E}_{2}$ were determined by radioimmunoassay (Beijing North Institute of Biological Technology, Beijing, China) and the serum levels of free FA (FFA) were measured using a Non-esterified Free Fatty Acids Assay kit (Nanjing Jiancheng Bio-Engineering Institute Co., Ltd., Nanjing, China) according to the manufacturer's protocol. Serum PA levels were examined by gas chromatography-mass spectrometry according to the method of Han et al (22).

IMTAG analysis. Soleus muscles were homogenized with normal saline buffer $(467 \mathrm{mmol} / 1 \mathrm{NaCl}, 10 \mathrm{mmol} / 1 \mathrm{KCl}$, $1 \mathrm{mmol} / 1 \mathrm{NaH}_{2} \mathrm{PO}_{4}, 4 \mathrm{mmol} / 1 \mathrm{NaHCO}_{3}, 8.4 \mathrm{mmol} / 1 \mathrm{Na}_{2} \mathrm{SO}_{4}$, $30 \mathrm{mmol} / 1 \mathrm{HEPES}, 10 \mathrm{mmol} / 1$ EDTA; $\mathrm{pH} 7.1$ with $\mathrm{KOH}$ ) to obtain $10 \%$ muscle homogenates. Subsequently, the levels of IMTAG were analyzed using the lipase glycerol kinase calorimetric method as previously described (23).

Histology analysis. Uterus, liver and soleus muscle samples were fixed in $10 \%$ formalin for 1 week at room temperature, embedded in paraffin, cut into $5-\mu \mathrm{m}$ thick sections, and stained 
with $0.4 \%$ hematoxylin for $5 \mathrm{~min}$ and $0.5 \%$ eosin for $4 \mathrm{~min}$ at room temperature. All sections were imaged using a Nikon Eclipse 80i fluorescence microscope (magnification, x100; Nikon Corporation, Tokyo, Japan).

Cell culture and drug treatment. The mouse myogenic cell line $\mathrm{C} 2 \mathrm{C} 12$ was purchased from the American Type Culture Collection (Manassas, VA, USA), cultured in high-glucose Dulbecco's Modified Eagle's medium at $37^{\circ} \mathrm{C}$ with $5 \% \mathrm{CO}_{2}$ in a cell incubator, and differentiated into myotubes with $2 \%$ horse serum (HyClone; GE Healthcare Life Sciences, Logan, UT, USA) for 4 days. PA and $\mathrm{E}_{2}$ (Sigma-Aldrich; Merck KGaA) were dissolved in ethanol and added to the culture medium. The cells were divided into six groups: Untreated (CON), absolute ethyl alcohol, $0.5 \mathrm{mmol} / 1 \mathrm{PA}, 0.5 \mathrm{mmol} / 1 \mathrm{PA}+1 \times 10^{-8} \mathrm{~mol} / 1 \mathrm{E}_{2}$ $\left(\mathrm{PA}+\mathrm{E}_{2}\right), 0.5 \mathrm{mmol} / 1 \mathrm{PA}+1 \times 10^{-8} \mathrm{~mol} / \mathrm{l} \mathrm{PPT}(\mathrm{PA}+\mathrm{PPT}$; Santa Cruz Biotechnology, Inc., Dallas, TX, USA) and $0.5 \mathrm{mmol} / 1$ $\mathrm{PA}+1 \times 10^{-8} \mathrm{~mol} / \mathrm{l} \mathrm{DPN}(\mathrm{PA}+\mathrm{DPN}$; Tokyo Chemical Industry Co., Ltd., Tokyo, Japan). $\mathrm{E}_{2}$, PPT and DPN were added to the medium $8 \mathrm{~h}$ prior to treatment with PA at $37^{\circ} \mathrm{C}$. Cells were treated with PA for $24 \mathrm{~h}$ at $37^{\circ} \mathrm{C}$, and cells were harvested for reverse transcription-semi-quantitative polymerase chain reaction (RT-sqPCR) and western blot analysis.

$R T$-sqPCR assay. Soleus muscles or myotubes formed by $\mathrm{C} 2 \mathrm{C} 12$ cells were used to detect the expression levels of ESR1, ESR2, PPAR $\alpha$, ACACA, PLIN2, CD36, FASN and GAPDH with RT-sqPCR using a PCR thermocycler (Omni Controls, Inc. Tampa, FL, USA). Total RNA was extracted using TRIzol ${ }^{\circledR}$ reagent (Thermo Fisher Scientific, Inc., Waltham, MA, USA) and reverse transcribed with OligodT primers and Moloney murine leukemia virus reverse transcriptase (Fermentas; Thermo Fisher Scientific, Inc., Pittsburgh, PA, USA) according to the manufacturer's protocols. The primers (Table I) were designed with Primer Premier 5 software (Premier Biosoft International, Palo Alto, CA, USA) and synthesized by Sangon Biotech Co., Ltd., (Shanghai, China). The reaction was performed in $25 \mu \mathrm{l}$ using Takara Ex Taq Polymerase (Takara Biotechnology Co., Ltd., Dalian, China), with the following thermocycling conditions: Initial denaturation at $95^{\circ} \mathrm{C}$ for $3 \mathrm{~min}, 32$ cycles of $30 \mathrm{sec}$ at $95^{\circ} \mathrm{C}, 30 \mathrm{sec}$ at $55^{\circ} \mathrm{C}$ and $30 \mathrm{sec}$ at $72^{\circ} \mathrm{C}$, with a final extension at $72^{\circ} \mathrm{C}$ for $10 \mathrm{~min}$. A total of 30 cycles were conducted for GAPDH. The PCR products (6 $\mu \mathrm{l}$ in each well) were analyzed by electrophoresis on a $3 \%$ agarose gel; the dye used for visualization was ethidium bromide. Gel-Pro Analyzer 3.1 software (Media Cybernetics, Inc., Rockville, MD, USA) was used to analyze the intensity of each band, and the relative expression levels of the genes were normalized to GAPDH. Each experiment was repeated three times.

Western blot assay. Soleus muscles or myotubes formed by $\mathrm{C} 2 \mathrm{C} 12$ cells were homogenized in ice-cold radioimmunoprecipitation assay buffer (Beyotime Institute of Biotechnology, Haimen, China). The total concentration of protein in sample was determined using a bicinchoninic acid assay. In total, $30 \mu \mathrm{g}$ protein was loaded in each lane. Proteins were separated by $10 \%$ SDS-PAGE and transferred to polyvinylidene difluoride membranes. Following blocking in a solution of $1 \mathrm{X}$ TBS, $0.1 \%$ Tween-20 (TBST) containing
Table I. Primers for reverse transcription-semi-quantitative polymerase chain reaction.

A, Rat

\begin{tabular}{llc}
\hline Gene & \multicolumn{1}{c}{ Primer sequence (5'-3') } & $\begin{array}{l}\text { Product } \\
\text { size, bp }\end{array}$ \\
\hline ESR1 & $\begin{array}{l}\text { F: CTGCCAAGGAGACTCGCTAC } \\
\text { R: AAGTGCCCATTTCATTTCG }\end{array}$ & 315 \\
ESR2 & F: TTGTGCCAGCCCTGTTACTA & 200 \\
& R: TACGCCGGTTCTTGTCTAT & \\
PPAR 2 & F: TGCTGTCCTCCTTGATGAAC & 270 \\
& R: GCTTGAGCACGTGCACAATC & \\
ACACA & F: AACCAGCACTCCCGATTC & 175 \\
& R: AGGCCAAACCATCCTGTAA & \\
PLIN2 & F: CTCTCGGCAGGATCAAAGAC & 171 \\
& R: CGTAGCCGACGATTCTCTTC & \\
FASN & F: CGGCGAGTCTATGCCACTAT & 398 \\
& R: ACACAGGGACCGAGTAATGC & \\
CD36 & F: CTCTGACATTTGCAGGTCCA & 214 \\
& R: CACAGGCTTTCCTTCTTTGC & \\
GAPDH & F: GCGAGATCCCGCTAACATCA & 178 \\
& R: CTCGTGGTTCACACCCATCA & \\
\hline
\end{tabular}

B, Mouse

\begin{tabular}{|c|c|c|}
\hline Gene & Primer sequence $\left(5^{\prime}-3^{\prime}\right)$ & $\begin{array}{l}\text { Product } \\
\text { size, bp }\end{array}$ \\
\hline
\end{tabular}

\begin{tabular}{lll}
\hline ESR1 & F: TCCTAACTTGCTCCTGGACAGG & 78 \\
& R: GTAGCCAGCAACATGTCA & \\
ESR2 & F: TTCTTTCTCATGTCAGGCACA & 123 \\
& R: CTCGAAGCGTGTGAGCATT & \\
PPAR $\alpha$ & F: CAAGTGCCTGTCTGTCGG & 236 \\
& R: TCTGGTCGTTGTTGGGCG & \\
ACACA & F: CCTGGAGTGGCAGTGGTCTTCG & 176 \\
& R: TCCTCCTCCCTCTGAGGCCTTG & \\
PLIN2 & F: CCCGCAACCTGACCCAGCAG & 114 \\
& R: CGCCTGCCATCACCCCCAAG & \\
CD36 & F: GAGCAACTGGTGGATGGTTT & 204 \\
& R: GCAGAATCAAGGGAGAGCAC & \\
FASN & F: GGAGGTGGTGATAGCCGGTAT & 140 \\
& R: TGGGTAATCCATAGAGCCCAG & \\
GAPDH & F: CATCTTCCAGGAGCGAGACC & 635 \\
& R: TGAAGTCGCAGGAGACAACC &
\end{tabular}

F, forward; R, reverse; bp, base pairs; PLIN2, perilipin 2; CD36, CD36 molecule; ACACA, acetyl-CoA carboxylase $\alpha$; FASN, fatty acid synthase; PPAR $\alpha$, peroxisome proliferator activated receptor $\alpha$; ESR, estrogen receptor.

$5 \%$ non-fat dry milk for $1 \mathrm{~h}$ at room temperature, the membranes were incubated with the following primary 
antibodies overnight at $4^{\circ} \mathrm{C}$ : PPAR $\alpha$ (1:400; cat. no. bs-23398R; Bioss Antibodies Inc., Woburn, MA, USA), ACACA (1:500; cat. no. 21923-1-AP; ProteinTech Group, Inc., Chicago, IL, USA), phosphorylated (p-)ACACA (1:500; cat. no. 11818; Cell Signaling Technology, Inc., Danvers, MA, USA), PLIN2 (1:500; cat. no. bs-1164R; Bioss Antibodies Inc.), CD36 (1:500; cat. no. sc-7309), FASN (1:500; cat. no. sc-48357; both Santa Cruz Biotechnology, Inc.), MAPK8 (1:500; cat. no. BS3630), p-MAPK8 (1:500; cat. no. BS4763; all Biogot Technology Co., Ltd., Nanjing, China), AKT serine/threonine kinase (AKT; 1:1,000; cat. no. 9272), p-AKT (1:1,000; cat. no. 4060; both Cell Signaling Technology, Inc.) and $\beta$-actin $(1: 1,000$; cat. no. TA-09; Beijing Zhongshan Golden Bridge Biotech, China). Then, the membranes were incubated with the secondary antibodies, horseradish peroxidase-conjugated goat anti-mouse (1:5,000; cat. no. S0002) and goat anti-rabbit (1:5,000; cat. no. S0001; both Affinity Biosciences, Cincinnati, $\mathrm{OH}, \mathrm{USA}$ ) for $1 \mathrm{~h}$ at room temperature. Detection was performed with enhanced chemiluminescence substrate (Thermo Fisher Scientific, Inc.) and quantification was performed with ImageJ software 1.48 (National Institutes of Health, Bethesda, MD, USA). The protein expression levels were normalized to $\beta$-actin. Subsequently, the ratio of phosphorylated/total protein was calculated. Each experiment was repeated three times.

Statistical analysis. Data are presented as the mean \pm standard error of the mean (in tables) or standard deviation (in figures). $\mathrm{P}<0.05$ was considered to indicate a statistically significant difference. Statistical analyses were performed using one-way analysis of variance followed by Fisher's Least Significant Difference (LSD) test. Statistical analyses were performed using SPSS software (version 23.0; IBM Corp., Armonk, NY, USA).

\section{Results}

Effects of $E_{2}$ on bodyweight and serum biochemical parameters in OVX rats. Female OVX rats exhibited a significant increase in body weight compared with age-matched SHAM controls (Table II). Food intake in OVX rats was increased, suggesting that surgical removal of ovaries induced hyperphagia. OVX rats exhibited significant increases in the serum levels of TG, TC, LDL-C, FFA and PA, but significant decreases in the serum levels of HDL-C and $\mathrm{E}_{2}$. Treatment with $\mathrm{E}_{2}$ decreased body weights, decreased the serum levels of TG, TC, LDL-C, FFA and PA, and increased the serum levels of HDL-C and $\mathrm{E}_{2}$ in the OVX group.

Effects of $E_{2}$ on pathological alterations following OVX. The volumes of the uterine gland and the uterus decreased in OVX rats compared with the sham control group (Fig. 1). The deposition of lipids increased in liver tissue, and infiltration of inflammatory cell into skeletal muscles were detected in the OVX group. Treatment with $\mathrm{E}_{2}$ partially reversed the size of the uterine gland, and decreased lipid deposition in the liver and aggregation of inflammatory cells in the skeletal muscles.

Effects of $E_{2}$ on insulin resistance and circulating levels of IMTAG in OVX rats. GTT and ITT analyses suggested that rats in the OVX group exhibited insulin resistance compared with the
SHAM group. However, rats in the $\mathrm{OVX}+\mathrm{E}_{2}$ group exhibited a significant improvement in insulin resistance (Fig. 2A-D), in addition to a decrease in body mass (Table II). Following insulin resistance, the protein expression levels of p-AKT and p-MAPK serve as opposing markers for insulin signaling. Western blotting suggested that the $\mathrm{p}-\mathrm{AKT} / \mathrm{AKT}$ ratio was significantly decreased and the p-MAPK8/MAPK8 ratio was markedly increased in the OVX group compared with the control. However, the p-AKT/AKT and p-MAPK8/MAPK8 ratios were restored following treatment with $\mathrm{E}_{2}$, in line with the GTT and ITT results (Fig. 2E and F). The levels of TG in muscle tissues were measured, and decreased estrogen levels were identified to be associated with a significant increase in the intracellular levels of IMTAG in OVX rats compared with the control (Fig. 2G). TG deposition was not observed in the muscle tissue following $\mathrm{H} \& \mathrm{E}$ staining (Fig. 1). In contrast, the intracellular levels of IMTAG were significantly decreased in the $\mathrm{OVX}+\mathrm{E}_{2}$ group compared with OVX alone (Fig. 2G). This suggested that treatment with $\mathrm{E}_{2}$ may decrease the synthesis of TG.

Effects of $E_{2}$ on gene expressions in OVX rats. The results of the present study suggested that the expression levels of ESR1 significantly decreased in OVX rats compared with the control group; however, ESR2 expression was increased in OVX rats. The expression levels of ESR1 and ESR2 were significantly restored in OVX rats following treatment with $\mathrm{E}_{2}$ (Fig. 3A and B). Since treatment with $\mathrm{E}_{2}$ decreased the levels of TG (Fig. 2G), the mRNA and protein expression levels of three proteins involved in TG synthesis were examined. The mRNA expression levels of ACACA, PLIN2 and FASN increased significantly in the OVX group compared with the control group, but were decreased in the OVX $+\mathrm{E}_{2}$ group compared with OVX alone (Fig. 3A and B). The protein expression levels of PLIN2 and FASN exhibited the same trend; however, that of ACACA was markedly unaltered. Therefore, the protein expression levels of p-ACACA, the activated form of ACACA, were examined. The results of western blotting suggested that the p-ACACA/ACACA ratio was decreased in the OVX group and was significantly restored following treatment with $\mathrm{E}_{2}$ (Fig. 3C and D). Additionally, the present RT-sqPCR and western blotting results suggested that the mRNA and protein expression levels of CD36 and PPAR $\alpha$ were decreased in OVX rats, and treatment with $\mathrm{E}_{2}$ partially reversed these effects. The alterations in the expression levels of ESR1, CD36 and PPAR $\alpha$ were similar following OVX and treatment with $\mathrm{E}_{2}$, suggesting that these factors may be involved in the same pathway.

Effects of $E_{2}, P P T$ and DPN on the expression levels of metabolism-associated factors in C2C12 cells treated with $P A$. Treatment with PA significantly decreased the expression levels of ESR1 mRNA in differentiated C2C12 cells compared with the control. In contrast, pretreatment with $\mathrm{E}_{2}$ or PPT led to a significant increase in the expression of ESR1 compared with PA treatment alone. However, the expression level of ESR2 significantly increased following treatment with PA compared with the control, and was partially restored by pretreating $\mathrm{C} 2 \mathrm{C} 12$ cells with $\mathrm{E}_{2}$ or PPT; although the difference between pretreated cells and non-pretreated cells was not significant (Fig. 4A and B). Similarly, the mRNA and 


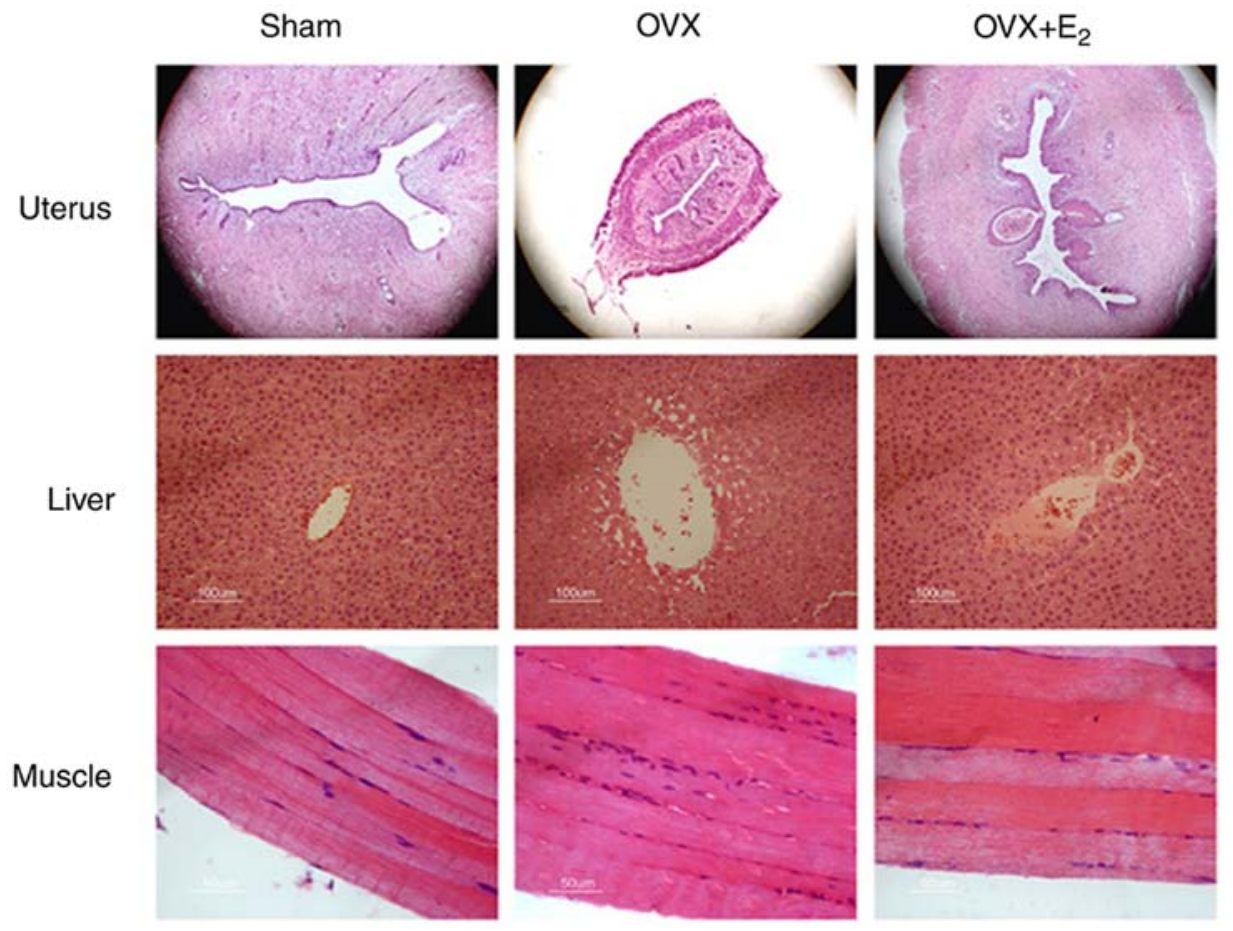

Figure 1. H\&E staining of uterus, liver and skeletal muscle following OVX and treatment with $\mathrm{E}_{2}$. Magnification, $\mathrm{x} 100$. OVX, ovariectomy; $\mathrm{E}_{2}, 17 \beta$-estradiol.

protein expression levels of PLIN2 and FASN significantly increased following treatment with PA, and these effects were reversed by pretreating $\mathrm{C} 2 \mathrm{C} 12$ cells with $\mathrm{E}_{2}$ or PPT, which was similarly to the mRNA expression profile of ACACA (Fig. 4A and B). Notably, the protein expression level of ACACA was markedly unaltered; however, the p-ACACA/ t-ACACA ratio was increased in the PA $+\mathrm{E}_{2}$ and PA + PPT groups compared with PA treatment alone (Fig. $4 \mathrm{C}$ and D). Additionally, the present RT-sqPCR and western blotting results suggested that the expression levels of PPAR $\alpha$ and CD36 were significantly decreased in the PA group compared with the control, and were increased in the PA $+\mathrm{E}_{2}$ and $\mathrm{PA}+$ PPT groups compared with PA treatment alone (Fig. 4A-D). However, the expression levels of the aforementioned factors were not significantly altered between the PA group and the PA + DPN group. Treatment with PA significantly decreased the p-AKT/AKT ratio and increased the p-MAPK8/MAPK ratio compared with the control. Pretreatment with $E_{2}$ or PPT reversed these effects, and pretreatment with DPN restored the levels of p-MAPK8/MAPK, suggesting that ESR1 activation improved insulin resistance in differentiated $\mathrm{C} 2 \mathrm{C} 12$ cells (Fig. 4E and F). Collectively, the present study investigated the role of $\mathrm{E}_{2}$ and $\mathrm{PA}$ in the metabolic alterations occurring in skeletal muscle cells (Fig. 5).

\section{Discussion}

Due to the increasing incidence of female obesity and the weight gain observed following menopause (24), the identification of novel strategies to decrease the occurrence rate of postmenopausal obesity is required. The present study suggested that treatment with $\mathrm{E}_{2}$ decreased body weight, intracellular levels of IMTAG, and serum levels of TG, TC and LDL-C following OVX. Additionally, OVX led to an increase in the expression levels of PLIN2, FASN and ACACA and a decrease in the expression levels of ESR1, CD36 and PPAR $\alpha$. Notably, treatment with $E_{2}$ reversed these effects, suggesting that $\mathrm{E}_{2}$ may inhibit $\mathrm{TG}$ synthesis, thus improving insulin resistance through the ESR1-CD36-PPAR $\alpha$ pathway in skeletal muscles.

OVX and ER-knockout mice were previously identified to develop obesity, and treatment with estrogen reversed these effects (25). The present study suggested that the body weight and the protein expression of p-MAPK8 increased following OVX, whereas the protein expression level of $\mathrm{p}-\mathrm{AKT}$ increased. In addition to the phosphorylation levels of MAPK8 and AKT, the GTT and ITT results suggested the occurrence of insulin resistance following OVX. Treatment with $\mathrm{E}_{2}$ decreased the body weight in OVX rats, and insulin resistance was improved, in line with previous investigations in human (26).

In normal skeletal muscle cells, FA uptake and TG synthesis are regulated by negative feedback mechanisms, so that lipid accumulation does not severely affect cellular function (27). Impaired regulation of FA uptake and TG synthesis in skeletal muscle is involved in insulin resistance (28). Following treatment with $\mathrm{E}_{2}$, and ESR1 and ESR2 agonists, muscle lipogenesis and TG accumulation were identified to be significantly decreased (29). The present results suggested that the levels of IMTAG increased in OVX rats, whereas the levels of IMTAG decreased following treatment with $\mathrm{E}_{2}$, suggesting an involvement of de novo TG synthesis in skeletal muscle following OVX. Additionally, treatment with $\mathrm{E}_{2}$ decreased synthesis of TG, as suggested by IMTAG detection; however, no alterations in lipid deposition were observed in skeletal muscles.

The expression of PLIN2 is specific of certain types of muscle fibers, and its expression level is increased in muscle fibers containing high levels of IMTAG (30). The present 
Table II. Effects of treatment with $\mathrm{E}_{2}$ in ovariectomized female rats.

\begin{tabular}{lccc}
\hline Parameters & Sham & OVX & OVX $+\mathrm{E}_{2}$ \\
\hline Body weight, g & $299.50 \pm 22.52$ & $406.25 \pm 30.75^{\mathrm{c}}$ & $312.75 \pm 31.34^{\mathrm{f}}$ \\
Food intake, g & $19 \pm 1.23$ & $26 \pm 2.65^{\mathrm{b}}$ & $21 \pm 1.78^{\mathrm{d}}$ \\
Triglycerides, mmol/l & $0.44 \pm 0.027$ & $0.56 \pm 0.070^{\mathrm{a}}$ & $0.38 \pm 0.056^{\mathrm{f}}$ \\
Total cholesterol, mmol/l & $1.61 \pm 0.023$ & $2.51 \pm 0.072^{\mathrm{c}}$ & $2.04 \pm 0.026^{\mathrm{f}}$ \\
High-density lipoprotein cholesterol, mmol/l & $0.70 \pm 0.0058$ & $0.54 \pm 0.071^{\mathrm{b}}$ & $0.68 \pm 0.12^{\mathrm{f}}$ \\
Low-density lipoprotein cholesterol, mmol/l & $0.93 \pm 0.23$ & $1.81 \pm 0.25^{\mathrm{c}}$ & $1.27 \pm 0.23^{\mathrm{d}}$ \\
Estradiol, pmol/l & $93.5 \pm 4.65$ & $72.5 \pm 12.71^{\mathrm{b}}$ & $128.75 \pm 6.24^{\mathrm{f}}$ \\
Free fatty acids, mmol/l & $0.41 \pm 0.05$ & $1.73 \pm 0.17^{\mathrm{a}}$ & $0.84 \pm 0.11^{\mathrm{d}}$ \\
Palmitic acid, $\mu \mathrm{g} / \mathrm{ml}$ & $210.81 \pm 2.63$ & $655.29 \pm 18.25^{\mathrm{b}}$ & $350.96 \pm 5.47^{\mathrm{e}}$
\end{tabular}

$\mathrm{n}=6$ in each group. ${ }^{\mathrm{a}} \mathrm{P}<0.05,{ }^{\mathrm{b}} \mathrm{P}<0.01,{ }^{\mathrm{c}} \mathrm{P}<0.001$ vs. sham control group; ${ }^{\mathrm{d}} \mathrm{P}<0.05,{ }^{\mathrm{e}} \mathrm{P}<0.01,{ }^{\mathrm{f}} \mathrm{P}<0.001$ vs. OVX group. OVX, ovariectomy; $\mathrm{E}_{2}$, $17 \beta$-estradiol.

A

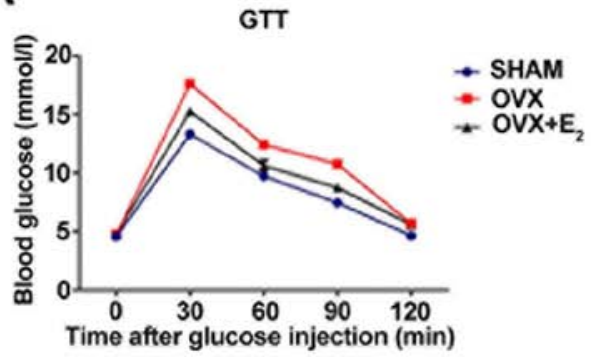

C

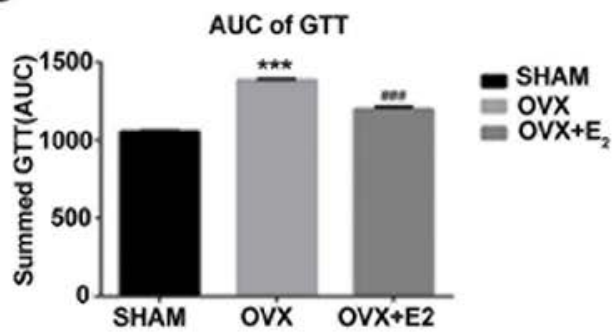

B

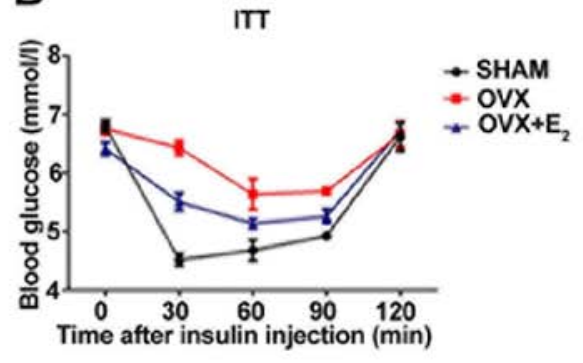

D

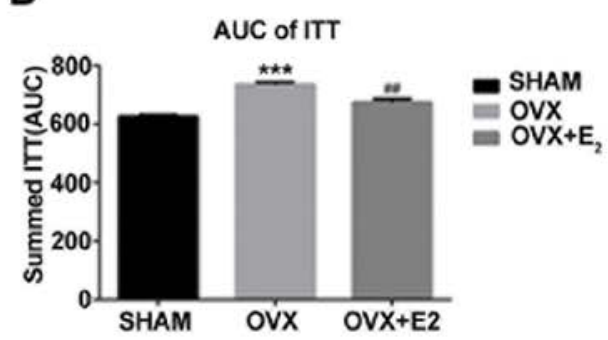

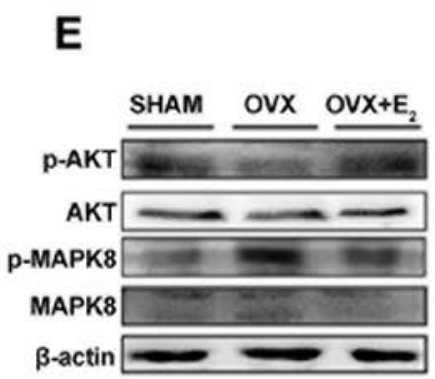
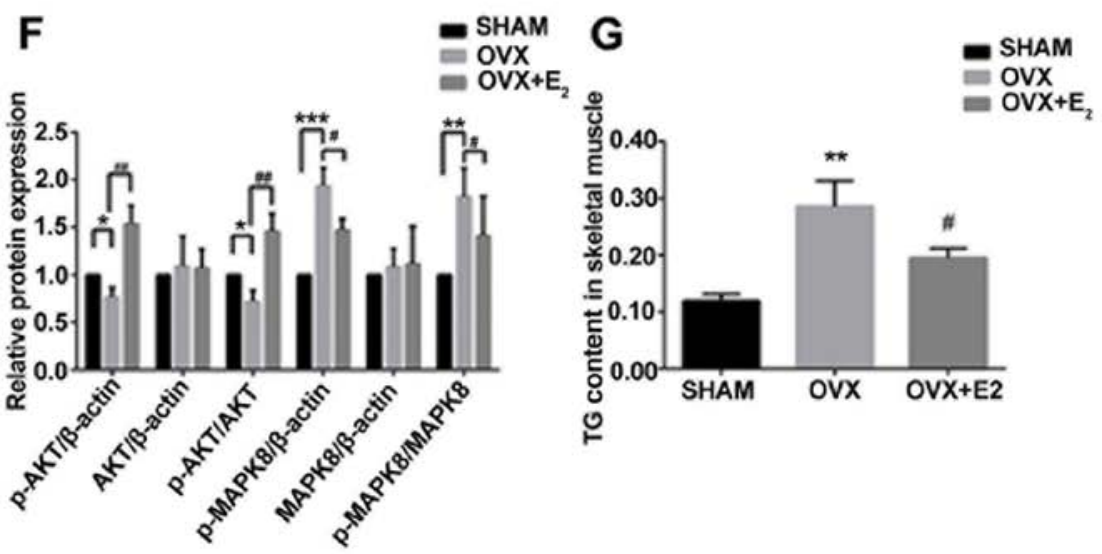

Figure 2. Effects of $\mathrm{E}_{2}$ on insulin resistance. (A) GTT analysis. (B) ITT analysis. (C) AUC of GTT analysis. (D) AUC of ITT analysis. (E) Protein expression levels of p-AKT, AKT, p-MAPK8 and MAPK8 in skeletal muscles. (F) Densitometric analysis of (E). (G) Levels of TG in skeletal muscles in various condi-

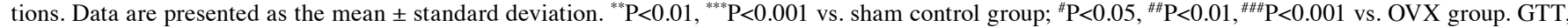
glucose tolerance test; ITT, insulin tolerance test; p-, phosphorylated; MAPK, mitogen-activated protein kinase; AKT, AKT serine/threonine kinase; TG, triglycerides; AUC, area under the curve; OVX, ovariectomy; $\mathrm{E}_{2}, 17 \beta$-estradiol.

results suggested that the mRNA and protein expression levels of PLIN2 were increased in skeletal muscles following OVX and in $\mathrm{C} 2 \mathrm{C} 12$ cells treated with PA. However, treatment with $E_{2}$ and activation of ESR1 decreased the expression level of 

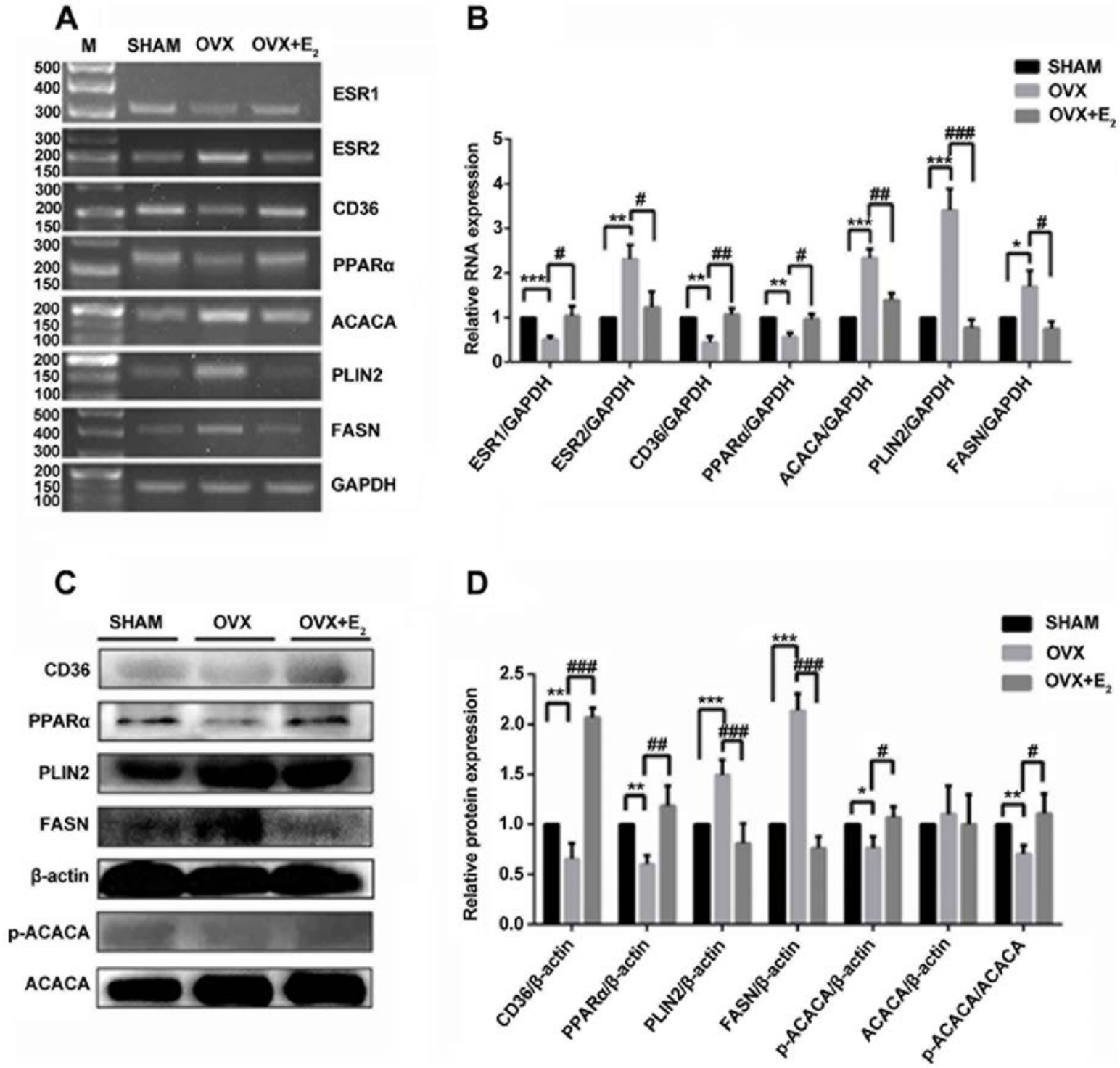

Figure 3. Analysis of gene expression in skeletal muscles. (A) RT-sqPCR and (B) densitometry analysis of ESR1, ESR2, CD36, PPAR $\alpha$, ACACA, PLIN2 and FASN in skeletal muscles in three conditions. (C) Western blot and (D) densitometry analyses of CD36, PPAR $\alpha$, PLIN2, FASN, p-ACACA and ACACA in skeletal muscles. Data are presented as the mean \pm standard deviation. ${ }^{*} \mathrm{P}<0.05,{ }^{* *} \mathrm{P}<0.01,{ }^{* * *} \mathrm{P}<0.001$ vs. sham control group. ${ }^{*} \mathrm{P}<0.05,{ }^{\# \#} \mathrm{P}<0.01$,

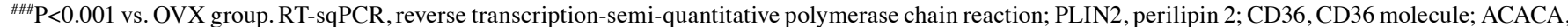
acetyl-CoA carboxylase $\alpha$; FASN, fatty acid synthase; PPAR $\alpha$, peroxisome proliferator activated receptor $\alpha$; ESR, estrogen receptor; OVX, ovariectomy; $\mathrm{E}_{2}$, $17 \beta$-estradiol; p-, phosphorylated; M, marker.

PLIN2 in muscle tissues and cells, suggesting that $\mathrm{E}_{2}$ may be involved in the expression level of PLIN2 by activating ESR1.

PPAR $\alpha$ regulates the expression levels of various genes involved in lipolysis and lipoprotein metabolism (31). Furthermore, OVX altered the expression levels of factors involved in lipogenesis, including FASN and ACACA, and in lipolysis, including PPAR $\alpha$. Notably, treatment with $\mathrm{E}_{2}$ and activation of ESR1 reversed the effects of OVX, in line with the previous study by Minnaard et al (32). A discrepancy between the mRNA and protein expression levels of ACACA was identified, possibly due to post-transcriptional modifications of ACACA. A limitation of the present study is that the mRNA expression levels of the genes investigated were assessed only by RT-sqPCR; however, quantitative PCR was not performed.

Previous studies using a rat model of OVX demonstrated that certain types of ER ligands may exhibit protective effects in skeletal muscle (33). In addition, it was observed that ESR1, but not ESR2, may be able to maintain mitochondrial function and metabolic homeostasis, and may exhibit a protective effect against inflammation $(34,35)$. The present results suggested that the expression levels of ESR1, PPAR $\alpha$ and CD36 was decreased following OVX or treatment with PA, and the levels of these factors increased following treatment with $E_{2}$ or pretreatment with PPT, suggesting that these three factors may be part of the same pathway.

CD36 is broadly expressed, and it was identified to be involved in FA and lipid metabolism in pathological conditions (36). CD36 is a transporter of FA, and it may represent a molecular target to protect myocytes against lipotoxicity (36). However, the effect of ESR1 activation on the expression level of CD36 remains unclear. The present results suggested that treatment with PPT, an ESR1 agonist, increased the mRNA and protein expression levels of CD36 suggesting that the 
A

M CON EtOH PA PA+E, PPT PPA
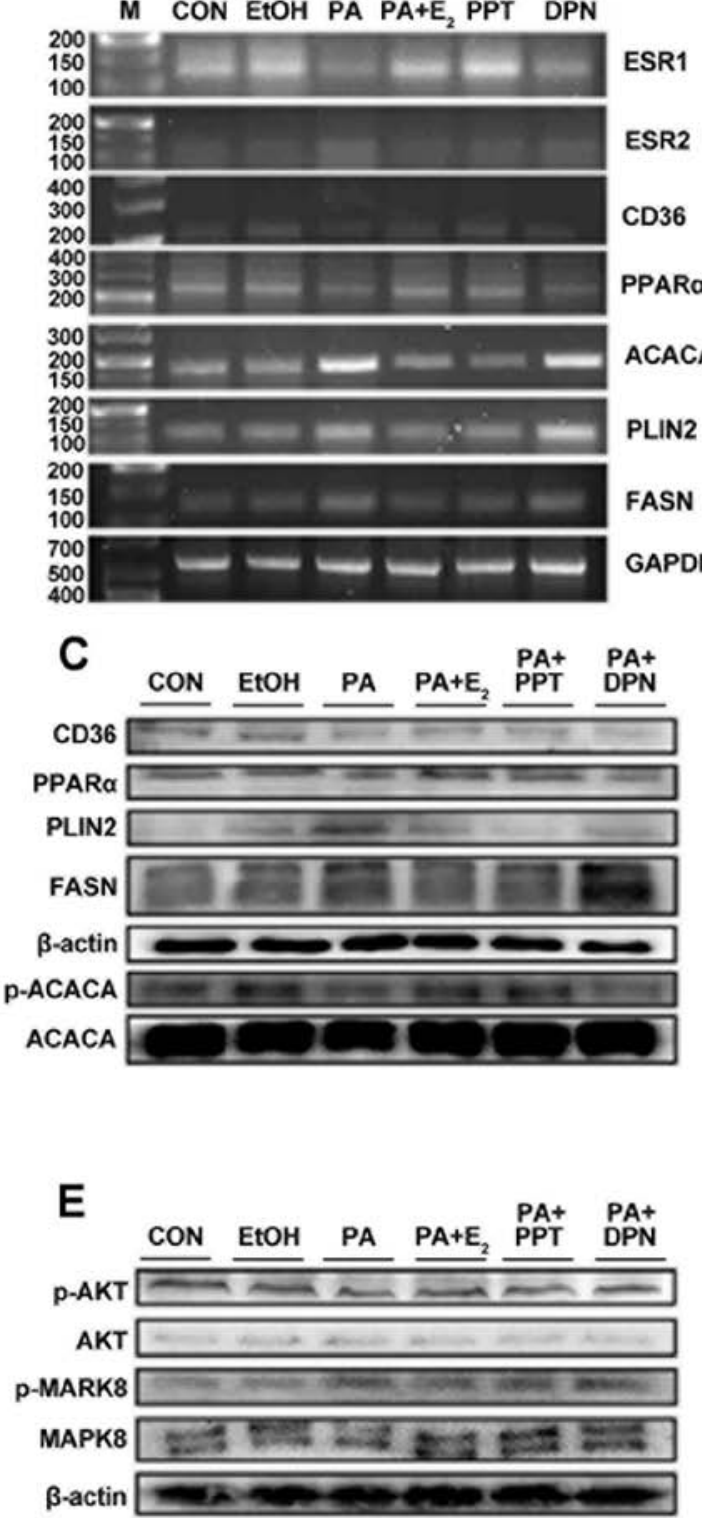

B

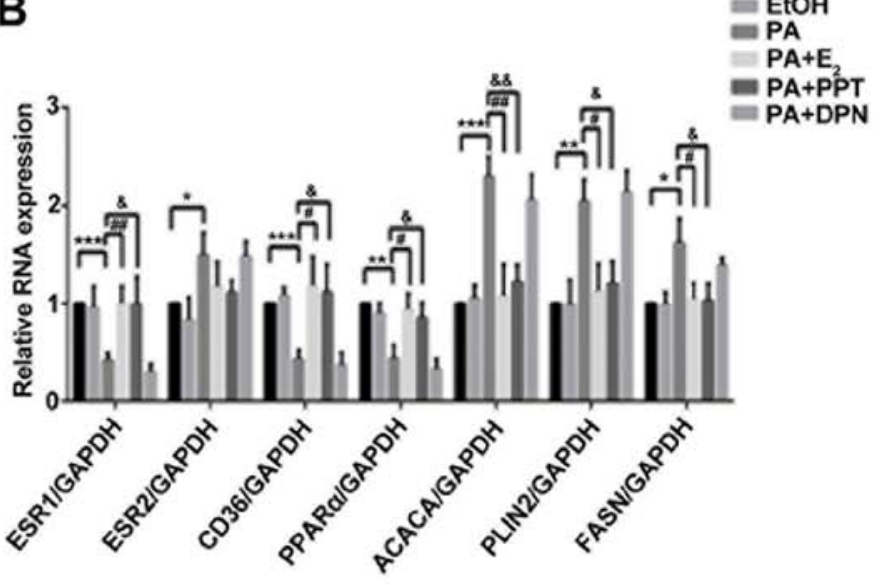

D

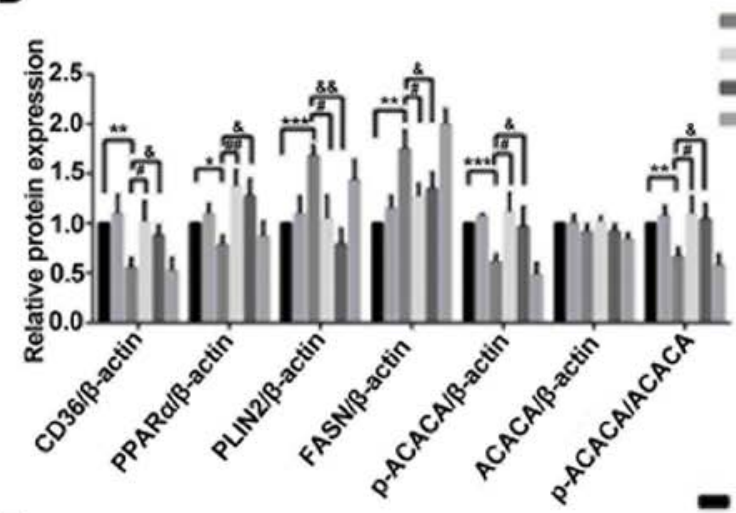

$\mathbf{F}$

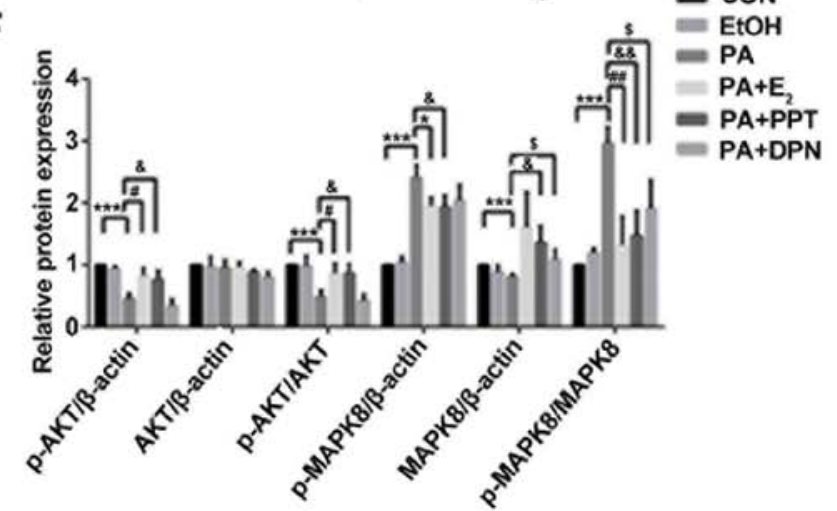

Figure 4. Analysis of gene expression in differentiated C2C12 cells. (A) RT-sqPCR and (B) densitometry analysis of ESR1, ESR2, CD36, PPAR $\alpha$, ACACA, PLIN2 and FASN expression in C2C12 cells. (C) Western blot and (D) densitometry analyses of CD36, PPAR $\alpha$, PLIN2, FASN, p-ACACA and ACACA in C2C12. (E) Western blot and (F) densitometry analyses of p-AKT, AKT, p-MAPK8 and MAPK8 in C2C12. Data are presented as the mean \pm standard devia-

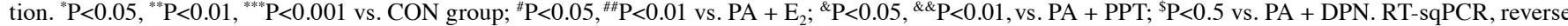
transcription-semi-quantitative polymerase chain reaction; PLIN2, perilipin 2; CD36, CD36 molecule; ACACA, acetyl-CoA carboxylase $\alpha$; FASN, fatty acid synthase; PPAR $\alpha$, peroxisome proliferator activated receptor $\alpha$; ESR, estrogen receptor; OVX, ovariectomy; $\mathrm{E}_{2}$, 17 $\beta$-estradiol; p-, phosphorylated; MAPK, mitogen-activated protein kinase; AKT, AKT serine/threonine kinase; CON, control; PA, palmitic acid; PPT, propylpyrazoletriol; DPN, diarylpropionitrile; EtOH, ethanol; M, marker.

activity of ESR1 in skeletal muscle may be modulated to treat diseases associated with metabolic syndrome.

The ESR2 signaling pathway is involved in the regulation of skeletal muscle growth and regeneration by stimulating anabolic pathways, activating satellite cells, and modulating immune response (33). In the present study, the expression level of ESR2 was examined in skeletal muscle and in cells treated with PA. Notably, the expression level of ESR2 was increased following OVX compared with the control. Treatment with PA increased the expression level of ESR2; however, pretreatment with DPN did not affect the expression levels of CD36, PPAR $\alpha$, ACACA, PLIN2 and FASN in C2C12 cells treated with PA, suggesting that ESR2 may not be involved in the ESR1-CD36-PPAR $\alpha$ pathway.

Collectively, the present results suggested that $E_{2}$, by activating ESR1, may modulate TG synthesis in skeletal muscle 


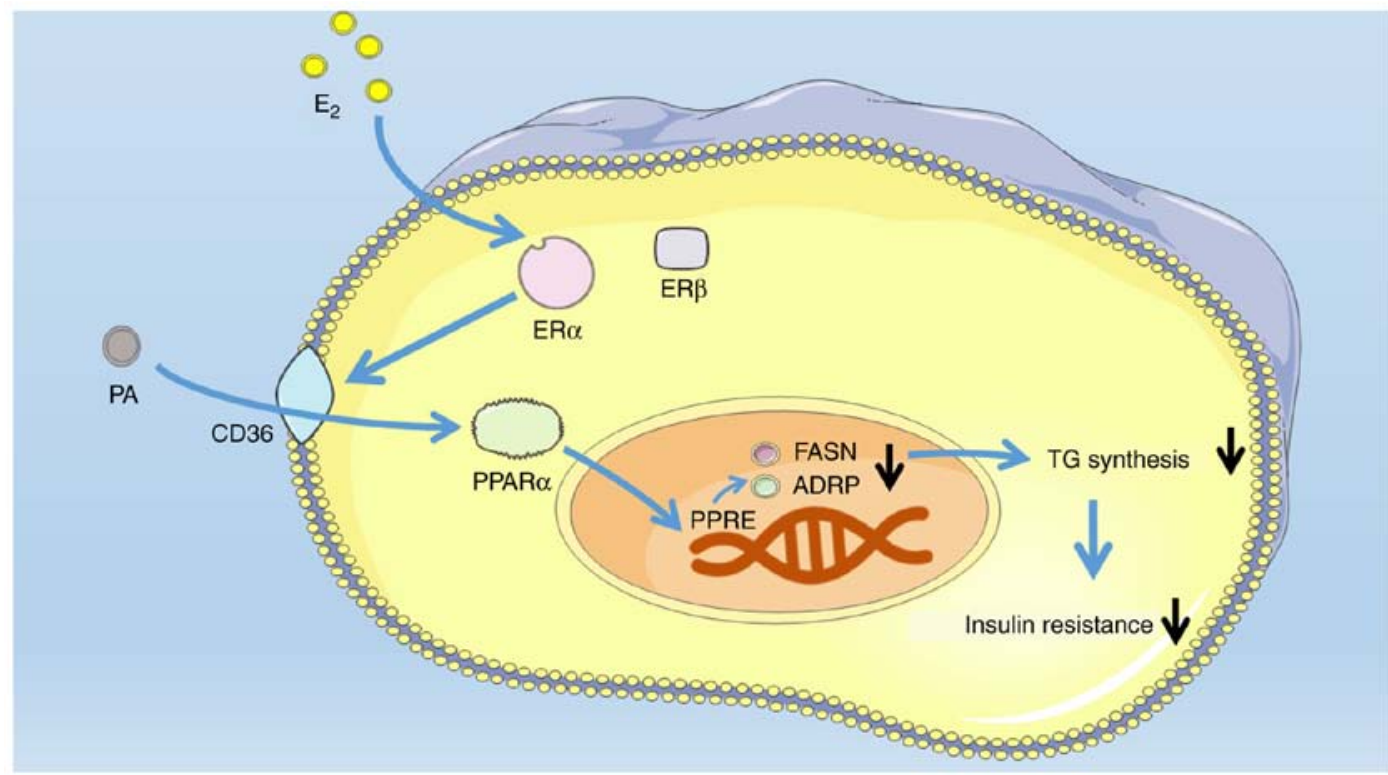

Figure 5. Schematic representation of the $\mathrm{E}_{2} / \mathrm{ESR} 1 / \mathrm{CD} 36 / \mathrm{PPAR} \alpha$ pathway in skeletal muscle cells. PPRE, PPAR response element; PPAR $\alpha$, peroxisome proliferator activated receptor $\alpha ; \mathrm{E}_{2}, 17 \beta$-estradiol; PA, palmitic acid; CD36, CD36 molecule; ESR, estrogen receptor; FASN, fatty acid synthase; TG, triglycerides; PLIN2, perilipin 2.

during menopause, and it may represent a novel complementary therapy to treat postmenopausal obesity. Notably, ESR1 and ESR2 were identified to have distinct functions, and further loss-of-function experiments are required to examine the function of each receptor in muscle cells.

\section{Acknowledgements}

The authors would like to thank Miss Li Gui and Mr Dake Huang at the Comprehensive Laboratory, Anhui Medical University for H\&E staining.

\section{Funding}

The present study was funded by The Scientific Research Foundation of Anhui Medical University (grant no. 2017XKJ027), The National Innovation and Entrepreneurship Project (grant no. 201710366019), The Natural Science Foundation of Anhui Province Education Department (grant no. KJ2017A186) and The Fund of Anhui Natural Science Foundation of China (grant no. 1808085MH233).

\section{Availability of data and materials}

The datasets used and/or analyzed during the present study are available from the corresponding author on reasonable request.

\section{Authors' contributions}

YL conceived and designed the study. QL, RL and GC performed the cell culture, RT-sqPCR and western blotting experiments. JW conducted the GTT/ITT experiment, and detected serum lipid and $\mathrm{E}_{2}$. BH performed the IMTAG and histology analysis. RL analyzed the data. CL and XZ conducted the animal experiments. YL drafted the manuscript.

\section{Ethics approval and consent to participate}

All animal experiments were reviewed and approved by The Ethics Committee of Anhui Medical University.

\section{Patient consent for publication}

Not applicable.

\section{Competing interests}

The authors declare that they have no competing interests.

\section{References}

1. Endo K, Weng H, Naito Y, Sasaoka T, Takahashi A, Fukushima Y and Iwai N: Classification of various muscular tissues using miRNA profiling. Biomed Res 34: 289-299, 2013.

2. Pierdominici M, Ortona E, Franconi F, Caprio M, Straface E and Malorni W: Gender specific aspects of cell death in the cardiovascular system. Curr Pharm Des 17: 1046-1055, 2011.

3. Welle $S$, Tawil R and Thornton CA: Sex-related differences in gene expression in human skeletal muscle. PLoS One 3: e1385, 2008.

4. Dewailly D, Robin G, Peigne M, Decanter C, Pigny P and Catteau-Jonard S: Interactions between androgens, FSH, anti-Müllerian hormone and estradiol during folliculogenesis in the human normal and polycystic ovary. Hum Reprod Update 22: 709-724, 2016.

5. Galluzzo P, Rastelli C, Bulzomi P, Acconcia F, Pallottini V and Marino M: 17beta-Estradiol regulates the first steps of skeletal muscle cell differentiation via ER-alpha-mediated signals. Am J Physiol Cell Physiol 297: C1249-C1262, 2009.

6. Sipilä S, Finni T and Kovanen V: Estrogen influences on neuromuscular function in postmenopausal women. Calcif Tissue Int 96: 222-233, 2015.

7. Hevener AL, Clegg DJ and Mauvais-Jarvis F: Impaired estrogen receptor action in the pathogenesis of the metabolic syndrome. Mol Cell Endocrinol 418: 306-321, 2015.

8. Tena-Sempere M: Neuroendocrinology in 2016: Neuroendocrine control of metabolism and reproduction. Nat Rev Endocrinol 13: 67-68, 2017. 
9. Martínez de Morentin PB, Lage R, González-García I, Ruíz-Pino F, Martins L, Fernández-Mallo D, Gallego R, Fernø J, Señarís R, Saha AK, et al: Pregnancy induces resistance to the anorectic effect of hypothalamic malonyl-CoA and the thermogenic effect of hypothalamic AMPK inhibition in female rats. Endocrinology 156: 947-960, 2015.

10. Mauvais-Jarvis F, Clegg DJ and Hevener AL: The role of estrogens in control of energy balance and glucose homeostasis. Endocr Rev 34: 309-338, 2013.

11. Moran AL, Warren GL and Lowe DA: Removal of ovarian hormones from mature mice detrimentally affects muscle contractile function and myosin structural distribution. J Appl Physiol (1985) 100: 548-559, 2006.

12. Klinge CM: Estrogens regulate life and death in mitochondria. J Bioenerg Biomembr 49: 307-324, 2017.

13. López $M$ and Tena-Sempere M: Estrogens and the control of energy homeostasis: A brain perspective. Trends Endocrinol Metab 26: 411-421, 2015.

14. Hamilton DJ, Minze LJ, Kumar T, Cao TN, Lyon CJ, Geiger PC, Hsueh WA and Gupte AA: Estrogen receptor alpha activation enhances mitochondrial function and systemic metabolism in high-fat-fed ovariectomized mice. Physiol Rep 4: e12913, 2016.

15. van Hall G: The physiological regulation of skeletal muscle fatty acid supply and oxidation during moderate-intensity exercise. Sports Med 45 (Suppl 1): S23-S32, 2015.

16. Kewalramani G, Bilan PJ and Klip A: Muscle insulin resistance: Assault by lipids, cytokines and local macrophages. Curr Opin Clin Nutr Metab Care 13: 382-390, 2010.

17. Tepavcevic S, Koricanac G, Zakula Z, Milosavljevic T, Stojiljkovic $M$ and Isenovic ER: Interaction between insulin and estradiol-17 $\beta$ in regulation of cardiac glucose and free fatty acid transporters. Horm Metab Res 43: 524-530, 2011.

18. Stavinoha MA, RaySpellicy JW, Essop MF, Graveleau C, Abel ED, Hart-Sailors ML, Mersmann HJ, Bray MS and Young ME: Evidence for mitochondrial thioesterase 1 as a peroxisome proliferator-activated receptor-alpha-regulated gene in cardiac and skeletal muscle. Am J Physiol Endocrinol Metab 287: E888-E895, 2004.

19. Mosti MP, Ericsson M, Erben RG, Schüler C, Syversen U and Stunes AK: The PPAR $\alpha$ agonist fenofibrate improves the musculoskeletal effects of exercise in ovariectomized rats. Endocrinology 157: 3924-3934, 2016.

20. Gorres BK, Bomhoff GL, Morris JK and Geiger PC: In vivo stimulation of oestrogen receptor $\alpha$ increases insulin-stimulated skeletal muscle glucose uptake. J Physiol 589: 2041-2054, 2011.

21. van de Heijning BJM, Oosting A, Kegler D and van der Beek EM: An increased dietary supply of medium-chain fatty acids during early weaning in rodents prevents excessive fat accumulation in adulthood. Nutrients 9: E631, 2017.

22. Han LD, Xia JF, Liang QL, Wang Y, Wang YM, Hu P, Li P and Luo GA: Plasma esterified and non-esterified fatty acids metabolic profiling using gas-chromatography mass spectrometry and its application in the study of diabetic mellitus and diabetic nephropathy. Anal Chim Acta 689: 85-91, 2011.

23. Tarchalski J, Guzik P and Wysocki H: Correlation between the extent of coronary atherosclerosis and lipid profile. Mol Cell Biochem 246: 25-30, 2003.

24. Salpeter SR, Walsh JM, Ormiston TM, Greyber E, Buckley NS and Salpeter EE: Meta-analysis: Effect of hormone-replacement therapy on components of the metabolic syndrome in postmenopausal women. Diabetes Obes Metab 8: 538-554, 2006.
25. Manrique C, Lastra G, Habibi J, Mugerfeld I, Garro M and Sowers JR: Loss of estrogen receptor signaling leads to insulin resistance and obesity in young and adult female mice. Cardiorenal Med 2: 200-210, 2012.

26. Marchand GB, Carreau AM, Weisnagel SJ, Bergeron J, Labrie F, Lemieux $\mathrm{S}$ and Tchernof $\mathrm{A}$ : Increased body fat mass explains the positive association between circulating estradiol and insulin resistance in postmenopausal women. Am J Physiol Endocrinol Metab 314: E448-E456, 2018.

27. Manco M, Mingrone G, Greco AV, Capristo E, Gniuli D, De Gaetano A and Gasbarrini G: Insulin resistance directly correlates with increased saturated fatty acids in skeletal muscle triglycerides. Metabolism 49: 220-224, 2000.

28. Strehlow K, Rotter S, Wassmann S, Adam O, Grohé C, Laufs K, Böhm M and Nickenig G: Modulation of antioxidant enzyme expression and function by estrogen. Circ Res 93: 170-177, 2003.

29. Huang L, Tepaamorndech S, Kirschke CP, Newman JW, Keyes WR, Pedersen TL and Dumnil J: Aberrant fatty acid metabolism in skeletal muscle contributes to insulin resistance in zinc transporter 7 (znt7)-knockout mice. J Biol Chem 293: 7549-7563, 2018.

30. Weigt C, Hertrampf T, Kluxen FM, Flenker U, Hülsemann F, Fritzemeier KH and Diel P: Molecular effects of ER alpha- and beta-selective agonists on regulation of energy homeostasis in obese female Wistar rats. Mol Cell Endocrinol 377: 147-158, 2013.

31. Duval C, Müller M and Kersten S: PPARalpha and dyslipidemia. Biochim Biophys Acta 1771: 961-971, 2007.

32. Minnaard R, Schrauwen P, Schaart G, Jorgensen JA, Lenaers E, Mensink M and Hesselink MK. Adipocyte differentiation-related protein and OXPAT in rat and human skeletal muscle: Involvement in lipid accumulation and type 2 diabetes mellitus. J Clin Endocrinol Metab 94: 4077-4085, 2009.

33. Velders M, Schleipen B, Fritzemeier KH, Zierau O and Diel P: Selective estrogen receptor- $\beta$ activation stimulates skeletal muscle growth and regeneration. FASEB J 26: 1909-1920, 2012.

34. Ribas V, Drew BG, Zhou Z, Phun J, Kalajian NY, Soleymani T, Daraei P, Widjaja K, Wanagat J, de Aguiar Vallim TQ, et al: Skeletal muscle action of estrogen receptor $\alpha$ is critical for the maintenance of mitochondrial function and metabolic homeostasis in females. Sci Transl Med 8: 334ra54, 2016.

35. Ribas V, Nguyen MT, Henstridge DC, Nguyen AK, Beaven SW, Watt MJ and Hevener AL: Impaired oxidative metabolism and inflammation are associated with insulin resistance in ERalpha-deficient mice. Am J Physiol Endocrinol Metab 298: E304-E319, 2010.

36. Glatz JFC and Luiken JJFP: Dynamic role of the transmembrane glycoprotein CD36 (SR-B2) in cellular fatty acid uptake and utilization. J Lipid Res 59: 1084-1093, 2018.

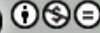

This work is licensed under a Creative Commons Attribution-NonCommercial-NoDerivatives 4.0 International (CC BY-NC-ND 4.0) License. 